\title{
Treatment Preferences for Chronic Low Back Pain: Views of Veterans and Their Providers
}

This article was published in the following Dove Press journal:

Journal of Pain Research

\author{
Ilana Belitskaya-Levy' \\ J David Clark ${ }^{2,3}$ \\ Mei-Chiung Shih' \\ Matthew J Bair (ID) ${ }^{4-6}$ \\ 'VA Cooperative Studies Program \\ Coordinating Center - Mountain View \\ Division, Palo Alto Healthcare System, \\ Mountain View, CA, USA; \\ ${ }^{2}$ Anesthesiology Service, VA Palo Alto \\ Health Care System, Palo Alto, CA, USA; \\ ${ }^{3}$ Department of Anesthesiology, \\ Perioperative and Pain Medicine, Stanford \\ University, Stanford, CA, USA; ${ }^{4}$ VA \\ HSR\&D Center for Health Information \\ and Communication, Roudebush VA \\ Medical Center, Indianapolis, IN, USA; \\ ${ }^{5}$ Department of Medicine, Indiana \\ University School of Medicine, \\ Indianapolis, IN, USA; ${ }^{6}$ Regenstrief \\ Institute, Inc., Indianapolis, IN, USA
}

Correspondence: Matthew J Bair VA HSR\&D Center for Health Information and Communication, Roudebush VA Medical Center, 148 I W. IOth St. (IIH), Indianapolis, IN 46202 , USA

Tel +l (3I7) 988-2058

Fax +I (317) 988-536I

Email mbair@iupui.edu
Purpose: This study was conducted to characterize chronic low back pain (cLBP) and to identify treatment histories and preferences for cLBP management among Veterans and primary care providers within the Veterans Affairs (VA) healthcare system.

Participants and Methods: Veterans with cLBP from five geographically diverse VA medical centers were identified using International Classification of Diseases (ICD) 9 and 10 codes from VA administrative data as were primary care providers at these same sites. From these data, Veterans (200/per site) and providers (160/per site) were selected and mailed surveys. Open-ended interview data were collected from a subset of Veterans and providers. Results: In total, 235 Veterans and 67 providers returned completed surveys. More than $80 \%$ of the Veteran respondents had daily back pain for more than 1 year. Most Veterans had tried several treatments for their pain with medications and physical therapy being the most commonly used. Veterans and providers had similar attitudes towards many cLBP treatments with the exception of psychological therapies that were more favored by providers. Openended interview data showed that Veterans and providers emphasized the need for multicomponent approaches to treatment.

Conclusion: Among Veterans, cLBP is typically of sustained duration, is relatively severe, and also interferes significantly with normal functioning. Veterans are experienced with respect to treatments and had similar attitudes towards many cLBP treatments as their providers, especially tailored approaches.

Keywords: low back pain, chronic pain, survey, preferences, primary care provider

\section{Introduction}

Chronic pain poses an enormous challenge to the United States (US) with total costs related to chronic pain including treatments and disability exceeding $\$ 600$ billion per year. ${ }^{1}$ The economic costs of low back pain alone amount to more than $\$ 100$ billion per year in the US. ${ }^{2}$ Unfortunately, optimal treatment strategies have not been identified for some of the most common causes of chronic pain including chronic low back pain (cLBP). In response, the National Academy of Medicine (formerly the Institute of Medicine) prioritized topics in need of comparative effectiveness research and listed the comparison of available treatments for low back pain well within the upper quartile on its top 100 list. $^{3}$ Adding to this concern is the recent release of the results of the Global Burden of Disease survey that concluded low back pain is the world's leading cause of years lived with disability ahead of headache, depression, and all other medical diseases. ${ }^{4}$

Specific populations within the US may be particularly vulnerable to chronic pain. For example, the prevalence of chronic pain is high among US Veterans 
with estimates approaching $50 \%$ of those seen in VA clinics. $^{5,6}$ In one study $44 \%$ of Veterans seen with chronic pain had pain related to the spine. ${ }^{5}$ In addition, data from the VHA Health Economics Research Center (HERC) document particularly high costs of care for Veterans with cLBP. ${ }^{7}$ Another important consequence of chronic pain is its contribution to the opioid crisis. A recent report from the National Academies of Sciences Engineering and Medicine specifically called for research into non-opioid chronic pain management alternatives to limit the demand for prescription opioids that may lead to abuse by patients or find their way into the community to be abused by others. ${ }^{8}$ Prescription opioid use among Veterans is particularly high, although significant declines have occurred over the past several years. ${ }^{9}$

To design pain treatment studies optimally, particularly those involving comparative effectiveness or pragmatic research strategies, a clear characterization of the target population is critical. As a foundation for planning these types of studies in Veterans, we collected such information. The main objectives of this study were to characterize cLBP in Veterans as well as to delineate commonly used treatments used. The study also sought to identify treatment preferences of both Veterans and primary care providers. Finally, we queried Veterans concerning barriers to participation in a cLBP treatment trial to understand how potential impediments to enrolment might be avoided in conducting and completing a study.

\section{Methods}

\section{Study Sample}

We obtained approval from the Stanford University Institutional Review Board (IRB) and Human Research Protection Program (HRPP) to use the VA's Corporate Data Warehouse database and to perform surveys of Veterans and providers. All Veteran participants provided verbal consent to be surveyed; the Stanford University IRB and HRPP approved this process. Our study was conducted in accordance with the Declaration of Helsinki. Permission to survey/interview providers was obtained from VA's Office of Labor Management Relations. To survey geographically diverse Veterans, we selected five VA sites for this effort: VA Ann Arbor Healthcare System (HCS), Roudebush (Indianapolis) VA Medical Center, VA Palo Alto HCS, VA San Diego HCS and VA Connecticut HCS.
Veterans with diagnoses related to cLBP and primary care providers were identified using data from the VA Corporate Data Warehouse. Patients attending general medical clinics at the selected sites were identified using a list of ICD 9 and 10 codes associated with chronic low back pain: ICD 9 (724.x (724.1, 724.2, 724.3, 724.4, 724.5 ...), ICD 10 (M51.2-, M54.4-, M54.5, S39.012). Veterans targeted for the survey had one or more of the diagnostic codes entered into their medical records and one or more primary care visits within the preceding 12 months. We identified approximately 60,000 Veterans at the five sites meeting these criteria. One thousand Veterans (200/per site) were selected to be sent surveys. We also identified a pool of approximately 2000 providers (physicians, physician assistants, and advanced practice nurses) at the five sites seeing Veterans with cLBP-related diagnoses. Eight hundred surveys (160/per site) were sent out to providers at the five sites.

\section{Surveys}

A Veteran and a provider survey were developed and included in Appendix 1. Investigator meetings were held to achieve consensus on survey items to include and achieve the overall goals to characterize cLBP characteristics, treatment histories, and patient attitudes that might be helpful in planning back pain studies within this population. We selected the alternative treatments asked about in the surveys after several investigator meetings and after consultation with several stakeholders. These stakeholders included 1) Cooperative Studies Program staff; 2) experts in complementary and integrative health; 3 ) members of the study planning committee; 4) advisors with expertise in pain, epidemiology, health services research, and survey methodology; and 5) members of the Humans Rights Committee at the Palo Alto VA. Surveys were mailed to Veterans' home addresses and to medical providers' assigned medical centers with addressed postage paid return envelopes.

\section{Veteran Survey Elements with Responses Chronic Low Back Pain Characteristics \\ - Frequency of back pain: never, some days, most days, every day \\ - Duration: less than 1 year, 1-4 years, 5 or more years \\ - Veteran understood source of pain/perceived cause: trauma, spinal stenosis, disc problems, other \\ - Radiation of pain to legs: neither, one, both}


- Average pain intensity for past week: 0-10 numerical scale anchored with no-pain (0) and worst imaginable (10)

- Past week pain interference with general activities: 0-10 numerical scale anchored with minimal (no interference - 0) and maximal (completely interferes - 10)

- Past week pain interference with enjoyment of life: 0-10 numerical scale anchored with not at all (0) and maximal (completely interferes -10 )

The pain intensity, interference and enjoyment items comprise the pain, enjoyment and general activity (PEG) score, ${ }^{10}$ and were originally composed from the Brief Pain Inventory (BPI). ${ }^{11}$

\section{Therapies Tried in the Past and Used Currently}

We assessed experience with and current use of 11 categories of commonly used back pain treatments including non-opioid analgesics, opioid analgesics, adjuvant analgesics, topical agents, muscle relaxants, psychological therapies, relaxation techniques, physical therapy, surgery, injections and complementary therapies including acupuncture, yoga and chiropractic. Space was provided for free-text listing of additional therapies.

\section{Attitudes Towards Therapies}

Veterans were asked to rank in order of preference 10 alternative treatments $(1=$ most preferred, $10=$ least preferred) for cLBP including acupuncture, chiropractic, marijuana, massage, medications, physical therapy, psychological therapies, spinal injections, surgery, and yoga. Free text space was provided for other therapies Veterans believed should be offered for their pain.

\section{Interest in Participating in a Back Pain Research Study} Veterans were asked their level of interest in participating in a back pain study with $0=$ not at all interested and $10=$ very interested. The following text was provided as a description of the study,

The VA is planning a study to identify the best approach to treat chronic low back pain. This study would involve patients being assigned to receive one of a few treatment options commonly recommended to patients suffering from low back pain. Most of the options would involve several weeks of active treatment followed by occasional assessments for up to one year. Some travel to a local VA clinic or possibly a VA hospital facility would be required.
There would be no charges for the treatments, and travel costs would be reimbursed.

\section{Patient Demographics}

Age, sex, race and distance from the nearest VA hospital facility, willingness to be contacted for an interview with open-ended questions to more fully understand their thoughts and attitudes about different back pain treatments.

\section{Provider Survey Elements}

Provider surveys began with the following description of the anticipated back pain study,

The VA is considering conducting a study to identify the optimal approach to the treatment of chronic low back pain. This study would involve patients being randomly assigned to receive one of several treatments similar to those described in this survey. Most of the options would involve several weeks of active treatment followed by occasional assessments for up to one year. Your input to this brief survey will help to shape the final design of the study.

We then assessed the following:

\section{Potential Study Participants}

Estimated number of patients in the provider's panel s/he believed could be referred.

\section{Attitudes Towards Therapies}

Providers were asked to rank in order of preference 10 alternative treatments $(1=$ most preferred, $10=$ least preferred) for cLBP including acupuncture, chiropractic, cannabis, massage, medications, physical therapy, psychological therapies, spinal injections, surgery, and yoga. Free text space was provided for therapies providers thought should be offered for back pain.

- Willingness to refer patients to the described cLBP study: Yes/No

- Willingness to be contacted for an interview to more fully understand their thoughts and attitudes about a VA-sponsored back pain study.

\section{Phone Interviews of Veterans and Providers}

We conveniently sampled and interviewed 30 Veterans and 8 providers to add depth to the survey data. Development of the interview guide was informed from our previous qualitative work and revised after consultation with two qualitative research experts. The Veterans who agreed and 
completed phone interviews were provided a $\$ 50$ incentive. A research assistant conducted the interviews. Interview questions focused on treatment preferences, treatment attitudes, and perceptions of barriers and facilitators to using specific treatments for chronic low back pain. Interview questions for Veterans and providers are included in Appendix 2. Interviews were audio-recorded and transcribed. Interview data were coded and placed in categories aligned with interview questions.

\section{Statistical Methods}

Numerical and graphical descriptive statistics were used to summarize the data overall and by study site. For continuous and ordinal outcomes, means, standard deviations, data ranges and boxplots were used. For categorical variables, proportions were used. Percentages in each category were calculated as a fraction of the number of observations in that category divided by the total number of observations minus the number of missing values in that category.
Spearman correlation coefficient and linear regression were used to assess relationships among variables.

\section{Results}

\section{Survey Response Rates Veterans}

Two hundred thirty-five surveys were returned $(23.5 \%$ response rate). The large majority $(87 \%)$ of the Veterans who returned the completed surveys did so within 2 months after the surveys were sent out. Of 235 Veterans who returned the surveys, 7 indicated that they did not have low back pain or experience any low back pain in the past 6 months (our criterion for cLBP). These surveys were excluded from analysis, leaving 228 responses for analysis.

\section{Providers}

Our response rate for provider surveys was substantially lower ( $\sim 8 \%, 67$ surveys). Fourteen indicated that they do

Table I Demographic Characteristics of Survey Responders (Veterans, $N=228$ )

\begin{tabular}{|c|c|c|c|c|c|c|}
\hline Question & $\begin{array}{l}\text { Overall } N= \\
228\end{array}$ & $\begin{array}{l}\text { Ann Arbor N = } \\
54\end{array}$ & $\begin{array}{l}\text { Indianapolis } \\
N=42\end{array}$ & $\begin{array}{l}\text { Palo Alto } N= \\
44\end{array}$ & $\begin{array}{l}\text { San Diego N = } \\
34\end{array}$ & $\begin{array}{l}\text { West Haven } \\
N=54\end{array}$ \\
\hline \multicolumn{7}{|l|}{ Age, years } \\
\hline Mean (SD) & $63(14)$ & $65(13)$ & $64(12)$ & $65(15)$ & $55(16)$ & $62(15)$ \\
\hline Median & 65 & 65 & 65 & 66 & 59 & 65 \\
\hline Range & [23-97] & [36-97] & [30-97] & [29-96] & [27-86] & [23-90] \\
\hline Missing & 5 & I & 2 & I & I & 0 \\
\hline \multicolumn{7}{|l|}{ Sex } \\
\hline Males, n (\%) & $195(86)$ & $47(87)$ & $33(79)$ & $40(91)$ & $28(82)$ & $47(87)$ \\
\hline Missing & $9(4)$ & $3(6)$ & $3(7)$ & $2(5)$ & 0 & I (2) \\
\hline \multicolumn{7}{|l|}{ Race n (\%) } \\
\hline White/Non-Hispanic & $130(57)$ & $37(69)$ & $24(57)$ & $21(48)$ & $15(44)$ & $33(6 \mathrm{I})$ \\
\hline White/Hispanic & $34(15)$ & $7(13)$ & $4(10)$ & $5(I I)$ & $7(2 \mathrm{l})$ & II (20) \\
\hline Black/African American & $19(8)$ & I (2) & $4(10)$ & $6(14)$ & $4(12)$ & $4(7)$ \\
\hline Asian & $10(4)$ & 0 & I (2) & $3(7)$ & $5(15)$ & I (2) \\
\hline Other & $8(4)$ & $2(4)$ & I (2) & I (2) & I (3) & $3(6)$ \\
\hline Two or more races & $13(6)$ & $2(4)$ & $3(7)$ & $5(\mathrm{II})$ & I (3) & $2(4)$ \\
\hline $\begin{array}{l}\text { Prefer not to answer or } \\
\text { missing }\end{array}$ & $14(6)$ & $5(9)$ & $5(12)$ & $3(7)$ & I (3) & 0 \\
\hline \multicolumn{7}{|c|}{ Distance to nearest VA, miles } \\
\hline Mean (SD) & $36(33)$ & $44(42)$ & $4 \mathrm{I}(40)$ & $37(29)$ & $34(27)$ & $23(16)$ \\
\hline Median & 27 & 38 & 28 & 25 & 27 & 20 \\
\hline Range & {$[2-300]$} & {$[5-300]$} & {$[2-190]$} & {$[2-100]$} & {$[5-120]$} & {$[2-55]$} \\
\hline Missing or unknown & 46 & 8 & 4 & 20 & 7 & 7 \\
\hline
\end{tabular}


not treat low back pain. These 14 providers returned blank surveys and were excluded from analysis, leaving 53 provider surveys available for analysis.

\section{Demographics of Survey Responders (Veterans)}

Provided in Table 1 are demographic characteristics of Veterans who responded to the survey overall and by study site. The mean age of the Veterans was 63 years (Standard Deviation (SD) $=14$ ) [Range=23-97]. Of the 228 respondents, $195(86 \%)$ were males and 130 (57\%) were white, non-Hispanic. The average distance to the nearest VA facility was 36 miles $(\mathrm{SD}=33)$, range = [2-300].

\section{Characteristics of Low Back Pain and Pain Interference in Responders}

Provided in Table 2 are the characteristics of low back pain and pain interference in Veteran respondents overall and by study site. Of the total, 132 (59\%) reported back pain every day in the past 6 months. One hundred seventyone $(78 \%)$ responders reported that their back pain lasted more than 4 years. The major sources of low back pain as understood by the Veterans were disc problems (41\%), arthritis (40\%), trauma (30\%), spinal stenosis (17\%), pinched nerve/sciatica (3\%), surgery $(2 \%)$ and scoliosis (1\%). Some of the responders indicated more than one source of low back pain. Thirty-seven (16\%) responders did not know the source of their low back pain. More than two-thirds $(\mathrm{n}=155,68 \%)$ of responders indicated that their pain travelled to one or both legs, possibly indicating a radicular component.

The mean PEG score, comprising items assessing pain intensity, interference with general activity, and interference with enjoyment of life was $5.9(\mathrm{SD}=2.5)$, representing moderately severe pain on the $0-10$ scale. The mean average pain intensity in the past week was $6.0(\mathrm{SD}=2.2)$ with $62(27 \%)$ reporting severe pain (score 8-10 on the scale $0-10)$. The mean pain interference with day-to-day activities was $5.8(\mathrm{SD}=2.9)$ with $70(31 \%)$ of the responders reporting that pain interfered with activities to a high degree (score $8-10$ on the scale $0-10$ ). The mean pain interference with the enjoyment of life was $6.0(\mathrm{SD}=2.9)$ with 80 responders $(35 \%)$ reporting that the pain interfered to a high degree (score $8-10$ on the $0-10$ scale).

\section{Current and Past Treatments}

Table 3 provides a summary of treatments that responders currently used or had tried in the past. We found significant variability in how frequent therapies were used. The majority of patients had tried oral analgesics and physical therapy, but a minority $(<25 \%)$ had tried yoga, acupuncture or psychological therapies. Other treatment options had intermediate levels of use (25-50\%).

The surveys allowed respondents to write in treatments tried or that they thought should be offered for cLBP. Other treatments that Veterans believed should be offered as well as other treatments that providers believed should be offered, included aquatic therapy, TENS (transcutaneous electrical nerve stimulation), and pain education classes.

\section{Treatment Preferences of Veterans and Providers}

Presented in Figures 1 and 2 are Veteran and provider low back treatment preferences, respectively. The three highest ranked treatment categories for Veterans were massage (46\%), physical therapy (40\%) and chiropractic care $(36 \%)$. Medications ranked fourth among Veterans with $35 \%$ ranking medications first to third most preferred. Other treatment options such as injections and surgery were far less favored by both Veterans and providers. Interestingly, marijuana was favored as an option by a significant number of Veterans (29\% of Veterans ranked 1st-3rd) but was strongly opposed by providers (91\% of providers ranked 8 th-10th). The three highest ranking treatment categories for providers were physical therapy with $92 \%$ of providers ranking it first to third; medications (49\% of providers ranked first to third) and psychological therapy ( $47 \%$ of providers ranked first to third).

We assessed the correlation between PEG scores and Veterans' treatment preference rankings. Higher PEG scores were positively correlated with preference for marijuana (Spearman correlation coefficient, $\rho=0.24$, $\mathrm{p}=0.0011)$, surgery $(\rho=0.21, \mathrm{p}=0.0039)$, and spinal injections $(\rho=0.19, \mathrm{p}=0.0078)$, and negatively correlated with preference for physical therapy $(\rho=-0.21, \mathrm{p}=$ 0.0036). Correlations for the other treatments were not significant.

\section{Interest in a Low Back Pain Study Veteran Responders}

On a scale from 0 to 10 , the average interest in participating in a low back pain study among Veteran responders was $7.1(\mathrm{SD}=3.5)$ with $127(59 \%)$ responders indicating that they would be highly interested in participating in a low back pain study (scores of 8-10). One hundred eighty-six $(85 \%)$ indicated that they would be willing to 
Table 2 Veteran Pain Severity, Frequency, Duration, Source, and Interference $(N=228)$

\begin{tabular}{|c|c|c|c|c|c|c|}
\hline Question & $\begin{array}{l}\text { Overall } \\
N=228\end{array}$ & $\begin{array}{l}\text { Ann Arbor } \\
N=54\end{array}$ & $\begin{array}{l}\text { Indianapolis } \\
N=42\end{array}$ & $\begin{array}{l}\text { Palo Alto } \\
N=44\end{array}$ & $\begin{array}{l}\text { San Diego } \\
N=34\end{array}$ & $\begin{array}{l}\text { West Haven } \\
N=54\end{array}$ \\
\hline \multicolumn{7}{|c|}{ Frequency of low back pain, n (\%) } \\
\hline Never & I (0) & 0 & 0 & I (2) & 0 & 0 \\
\hline Some days & $34(15)$ & $10(19)$ & $5(12)$ & $5(\mathrm{II})$ & $2(6)$ & $12(23)$ \\
\hline Most days & $58(26)$ & $13(25)$ & $10(24)$ & $14(32)$ & $9(26)$ & $12(23)$ \\
\hline Everyday & 132 (59) & $30(57)$ & $26(62)$ & $24(55)$ & $23(68)$ & $29(55)$ \\
\hline Missing & 3 & I & 1 & 0 & 0 & 1 \\
\hline \multicolumn{7}{|c|}{ Duration of low back pain, $n$ (\%) } \\
\hline Less than I year & $14(6)$ & $3(6)$ & $2(5)$ & $2(5)$ & I (3) & $6(12)$ \\
\hline $\mathrm{I}-4$ years & $33(15)$ & $7(13)$ & $7(18)$ & $2(5)$ & $8(25)$ & $9(18)$ \\
\hline 5 years or more & $17 \mid(78)$ & $42(8 I)$ & 31 (78) & $39(91)$ & $23(72)$ & $36(7 I)$ \\
\hline Missing & $10(4)$ & 2 & 2 & 1 & 2 & 3 \\
\hline \multicolumn{7}{|c|}{ Source of low back pain, n (\%) } \\
\hline Multiple sources & 104 (48) & $27(52)$ & $21(53)$ & $19(49)$ & $16(50)$ & $21(40)$ \\
\hline Trauma & $68(3 \mathrm{I})$ & $10(19)$ & $15(38)$ & $16(4 I)$ & $15(47)$ & $12(23)$ \\
\hline Trauma only & $2 I(10)$ & $3(6)$ & $4(10)$ & $5(13)$ & $3(9)$ & $6(11)$ \\
\hline Spinal stenosis & $38(18)$ & $10(19)$ & $6(15)$ & $8(2 I)$ & $4(13)$ & $10(19)$ \\
\hline Spinal stenosis only & $5(2)$ & I (2) & I (3) & 0 & I (3) & $2(4)$ \\
\hline Disk problem & $94(44)$ & $27(52)$ & $19(48)$ & $17(44)$ & $13(4 \mid)$ & $18(34)$ \\
\hline Disk problem only & $21(10)$ & $4(8)$ & $5(13)$ & $3(8)$ & $3(9)$ & $6(11)$ \\
\hline Arthritis & $92(43)$ & $25(48)$ & $17(43)$ & $17(44)$ & II (34) & $22(42)$ \\
\hline Arthritis only & $16(7)$ & $3(6)$ & $3(8)$ & $3(8)$ & $2(5)$ & $5(9)$ \\
\hline Unknown & $37(17)$ & II (2I) & $4(10)$ & $8(21)$ & $5(16)$ & $9(17)$ \\
\hline Unknown only & $30(14)$ & $10(19)$ & $3(8)$ & $7(18)$ & $4(13)$ & $6(11)$ \\
\hline Other & $38(18)$ & $9(17)$ & $9(23)$ & $5(13)$ & $5(16)$ & $10(19)$ \\
\hline Other only & $19(9)$ & $4(8)$ & $3(8)$ & $2(5)$ & $3(9)$ & $7(2)$ \\
\hline Missing & 12 & 2 & 2 & 5 & 2 & 1 \\
\hline \multicolumn{7}{|c|}{ Pain travels to legs, n (\%) } \\
\hline Both & $78(34)$ & $15(28)$ & $20(48)$ & $19(43)$ & $9(26)$ & $15(28)$ \\
\hline One & $75(33)$ & $17(3 \mid)$ & $12(29)$ & $14(32)$ & $17(50)$ & $15(28)$ \\
\hline Neither & $60(26)$ & $19(35)$ & $9(2 I)$ & $9(20)$ & $7(21)$ & $16(30)$ \\
\hline Missing & $15(7)$ & $3(6)$ & $\mathrm{I}(2)$ & $2(5)$ & I (3) & $8(15)$ \\
\hline \multicolumn{7}{|c|}{ PEG score, scale 0-10 } \\
\hline Mean (SD) & $5.9(2.5)$ & $5.8(2.5)$ & $6.2(2.6)$ & $6.3(2.4)$ & $6.5(2.2)$ & $5.1(2.5)$ \\
\hline \multicolumn{7}{|c|}{ Average pain intensity in the past week, scale $0-10$} \\
\hline Mean (SD) & $6.0(2.2)$ & $5.8(2.3)$ & $6.1(2.2)$ & $6.5(2.1)$ & $6.1(2.1)$ & $5.7(2.4)$ \\
\hline Median & 6 & 6 & 7 & 7 & 6.5 & 6 \\
\hline Missing & 3 & 1 & 1 & 1 & 0 & 0 \\
\hline \multicolumn{7}{|c|}{ Pain interference with day-to-day activities in the past week, scale $0-10$} \\
\hline Mean (SD) & $5.8(2.9)$ & $5.9(2.9)$ & $6.0(3.1)$ & $6.0(2.8)$ & $6.7(2.5)$ & $4.6(2.7)$ \\
\hline Median & 6 & 6 & 5.5 & 6.5 & 7 & 5 \\
\hline Missing & 3 & I & 2 & 0 & 0 & 0 \\
\hline
\end{tabular}

(Continued) 
Table 2 (Continued).

\begin{tabular}{|l|l|l|l|l|l|l|}
\hline Question & $\begin{array}{l}\text { Overall } \\
\mathbf{N}=\mathbf{2 2 8}\end{array}$ & $\begin{array}{l}\text { Ann Arbor } \\
\mathbf{N = \mathbf { 5 4 }}\end{array}$ & $\begin{array}{l}\text { Indianapolis } \\
\mathbf{N = \mathbf { 4 2 }}\end{array}$ & $\begin{array}{l}\text { Palo Alto } \\
\mathbf{N}=\mathbf{4 4}\end{array}$ & $\begin{array}{l}\text { San Diego } \\
\mathbf{N}=\mathbf{3 4}\end{array}$ & $\begin{array}{l}\text { West Haven } \\
\mathbf{N}=\mathbf{5 4}\end{array}$ \\
\hline
\end{tabular}

Table 3 Overall Current and Past Treatments Used (Veterans, $N=228$ )

\begin{tabular}{|l|l|l|}
\hline & Past & Current \\
\hline Pain relievers (non-opioid), yes (\%) & $186(93)$ & $134(67)$ \\
Physical Therapy, yes (\%) & $184(89)$ & $125(64)$ \\
Pain reliever (opioid), yes (\%) & $119(60)$ & $59(31)$ \\
Pain relievers (adjuvant), yes (\%) & $73(37)$ & $56(31)$ \\
Topical agents, yes (\%) & $121(59)$ & $61(33)$ \\
Muscle relaxants, yes (\%) & $105(52)$ & $46(25)$ \\
Cognitive, behavioral, or psychological therapies, yes (\%) & $50(25)$ & $34(19)$ \\
Relaxation techniques, yes (\%) & $90(44)$ & $59(32)$ \\
Surgery, yes (\%) & $46(22)$ & $21(12)$ \\
Injections, yes (\%) & $79(38)$ & $20(12)$ \\
Yoga, yes (\%) & $42(20$ & $16(9)$ \\
Acupuncture, yes (\%) & $57(27)$ & $32(19)$ \\
Chiropractic, yes (\%) & $118(57)$ & \\
\hline
\end{tabular}

participate in the follow-up telephone interview to discuss their thoughts and attitudes towards back pain treatments and towards participating in a VA back pain study. Higher

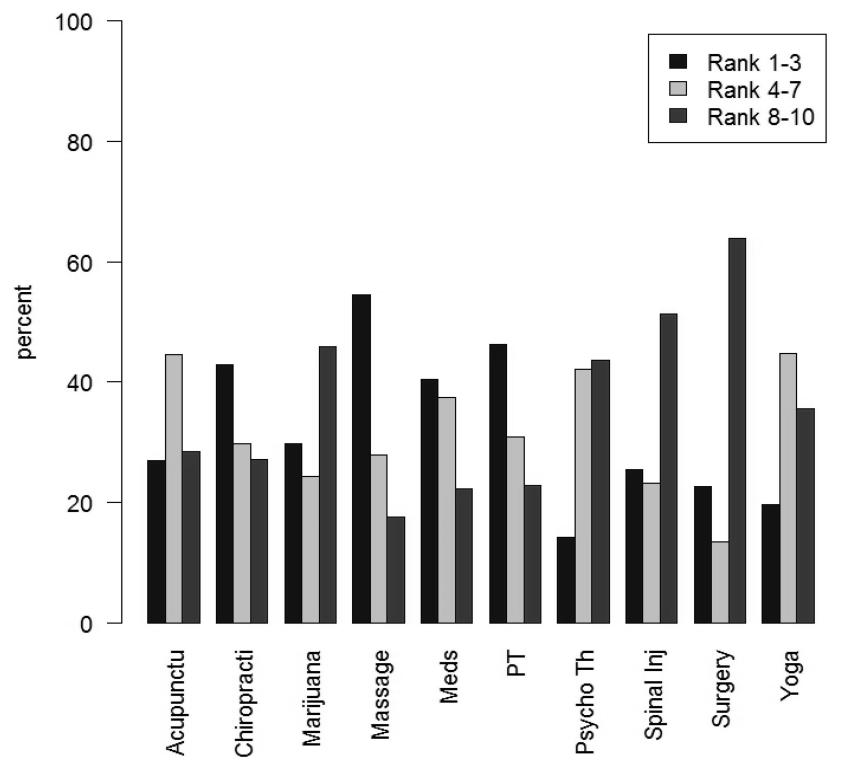

Figure I Low back pain treatment preferences of Veterans.
PEG scores were positively correlated with interest in participating in a low back study (slope $=0.31, \mathrm{p}=$ 0.0013).

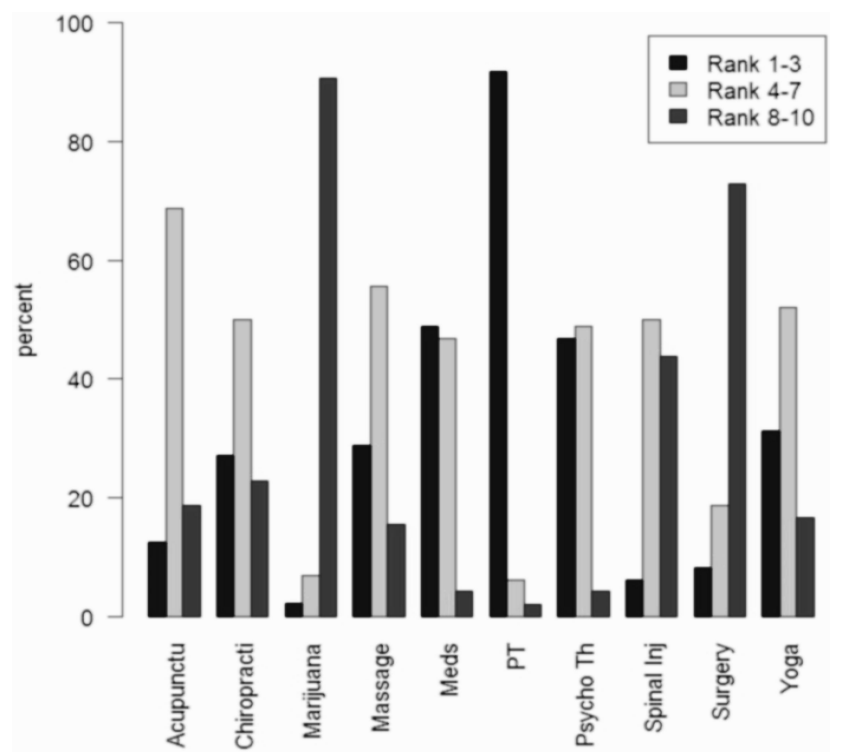

Figure 2 Low back pain treatment preferences of providers. 


\section{Provider Responders}

Thirty-five (66\%) providers who responded to the survey said they would refer patients to a VA study that aims to identify the optimal approach to the treatment of cLBP. Twenty-one (40\%) providers said that they would be willing to discuss their thoughts and attitudes about referring patients to participate in a VA-sponsored back pain study.

\section{Interviews}

Thirty Veterans participated in semi-structured interviews. In the interviews, participants discussed the treatment goals most important to them, their most and least preferred treatments to include in a cLBP trial, their reasons behind the most and least preferred treatment options, their willingness to participate in a trial, any concerns, barriers, and challenges to participating in a trial, and what they perceived as the ideal treatment program.

Interviews demonstrated significant variability in treatment experiences and individual needs. Opinions varied greatly on the perceived effectiveness of different pain treatments. For example, in the context of physical therapy, some had never tried physical therapy while others had tried it, but not for cLBP. Some Veterans had tried it but did not like physical therapy because they believed it did not help relieve their pain, or sessions led to more pain. Another Veteran characterized his physical therapy experience as a "waste of time" and another said it could have been more helpful if it was "tailored." Other Veterans "loved it (physical therapy)."

The most important treatment goals reported by Veterans were pain relief $(\mathrm{n}=16)$ and improved ability to function $(\mathrm{n}=11)$. Consistent with our survey findings, the most preferred treatment options were physical therapy $(\mathrm{n}=12)$, acupuncture $(\mathrm{n}=10)$, and chiropractic care ( $\mathrm{n}$ $=8$ ). When probed on the reasons behind these preferences, Veterans related a good treatment response in the past $(\mathrm{n}=8)$ and had confidence in the therapy $(\mathrm{n}=8)$. On the other hand, medications $(\mathrm{n}=10)$, surgery $(\mathrm{n}=5)$, and physical therapy $(n=5)$ were the least preferred treatments because they had already tried in the past $(\mathrm{n}=11)$ or there was not confidence in the approach $(n=7)$.

All Veterans interviewed $(\mathrm{n}=30)$ were "very willing" to participate in a cLBP trial. When asked why they were enthusiastic about participating, the most common reasons were a desire to try new treatments $(n=9)$ and their wish to find a more effective treatment than they were currently using $(\mathrm{n}=7)$. Few Veterans expressed concerns about participating in a trial. However, one Veteran offered: "I do not want to participate if I am asked to take more medication." In a similar vein, another Veteran did not want to participate if "the study only focused on medication." Upon probing, Veterans were concerned about the potential for addiction and "not feeling like myself" due to medication side effects. The most common barrier $(n=9)$ to participating in a cLBP trial was the potential travel distances involved. To overcome this barrier, Veterans wanted to be compensated for travel to the treatment facility.

When asked about the ideal treatment approach, several Veterans wanted a "holistic program." Specifically, one Veteran shared that he wanted "a team of doctors who worked together to understand my pain." Individualized pain care was mentioned: " ... develop a program specifically tailored to my needs." Overall, most Veterans were curious about or interested in trying more "holistic" or "alternative" therapies. Several Veterans reported that they do not believe their needs are being met with more standardized, "one-size-fits-all" approaches to back pain relief. Specific examples given were the use of analgesics, including opioids. Interestingly, weight management was mentioned several times $(\mathrm{n}=5)$ as a desirable pain management strategy to include in a trial.

Only 8 providers were interviewed. All expressed interest in referring Veterans to a cLBP trial and almost all expressed a desire for a multi-disciplinary, multi-modal approach to pain care.

\section{Discussion}

Chronic pain is common and costly with cLBP representing a major cause of disability worldwide. ${ }^{4}$ Veterans have particularly high rates of chronic pain with cLBP representing one of the most common etiologies. ${ }^{5,6}$ Several sets of guidelines for the treatment of cLBP and other forms of musculoskeletal pain are available, although comparative effectiveness data and data reflecting combination or multimodal treatments are largely lacking. ${ }^{3}$ To plan studies of highest impact for cLBP, we need information on the characteristics of Veterans suffering from cLBP, characteristics of the pain itself, an understanding of treatments used and desired by Veterans, and, importantly, the attitudes towards treatments of the medical providers. Our study provided information in each of these dimensions with some of the key findings being, 1) cLBP is of relatively high intensity and causes significant functional interference among Veterans, 2) cLBP sufferers have typically used several treatments with medications and 
physical therapy being some of the more commonly used approaches, 3) Veterans and their medical providers shared a preference for physical approaches and medications while both groups generally preferred interventional and surgical approaches the least, and 4) one of the most commonly recommended, first-line cLBP treatments listed in guidelines, psychological approaches, was highly favored by providers but ranked low among patients. Interviews with patients and providers revealed that patients and providers were interested in approaches offering a flexible range of options for treatment; tailored to an individual patient's preferences.

While chronic pain was previously established to be prevalent among Veterans, our results further describe the nature of cLBP as experienced in this population. Based on our selection of ICD9/10 codes used to target the surveys, we expected that the duration of back pain was likely to be long. For example, spinal stenosis, lumbago and sciatica tend to be persistent conditions. Also supporting that expectation was the average age of the Veteran respondents (63 years); cLBP prevalence increases significantly until late middle age. ${ }^{12}$ Consistent with these expectations, $78 \%$ reported pain present for more than 4 years, and the majority (59\%) experienced pain every day in the 6 months prior to completing the survey. In addition to being persistent, the pain was severe and interfered significantly with daily activities. Embedded in our survey was the PEG (pain, enjoyment, general activity) scale, a three-item tool derived from the Brief Pain Inventory and validated in Veterans. ${ }^{10}$ The average score of 5.9 indicates a moderate-severe overall cLBP severity and functional interference in this population and consistent with normative data from 36 pain clinics in Australia and New Zealand. ${ }^{13}$ These findings suggest that many Veterans with cLBP experience "high-impact" chronic pain defined as persistent pain with substantial restriction of life activities lasting 6 months or more. ${ }^{14}$ This designation has been associated with greater health-care utilization, lower quality of life, and the presence of pain in other locations. ${ }^{14}$

It may also be significant that more than two-thirds of the respondents experienced pain radiating to one or both legs. Radiating pain is often taken as a sign of possible radiculopathy from nerve root compression. Treatments such as epidural steroid injections and spinal cord stimulation are often targeted to those with radiating pain as it is believed that these therapies may be more effective for those with radicular symptoms. ${ }^{15,16}$ We did not attempt to match reported or charted diagnoses with pain severity or the nature of pain symptoms as it is common for multiple cLBP-related diagnoses to be documented in an individual Veteran's chart, eg spinal stenosis and degenerative disc disease. However, the high prevalence of radiating pain among these Veterans suggests that studies examining the effects of treatments on both axial and radicular pain may be important.

Few studies have assessed patient preferences for specific cLBP treatments, ${ }^{17}$ and essentially none to this point have compared patient and provider preferences. Our list of treatment options largely contained conservative, early-step treatments that are commonly used and recommended in treatment guidelines. $^{18-20}$ These include psychological therapies (cognitive behavioral therapy), physical therapy, and medications. Additionally, complementary and integrative approaches included yoga, massage, and chiropractic care were popular. Both patients and providers favored the commonly used treatments: medications and physical therapy. However, aside from physical therapy, Veterans tended to rank therapies requiring only passive, rather than active, participation highly, such as massage and chiropractic care.

Providers differed in their preference for psychological therapies, a group of approaches including cognitive behavioral therapy, acceptance-commitment therapy, mindfulness training and others. ${ }^{21,22}$ Less than $15 \%$ of Veterans ranked psychological therapies among their top three choices, and this category of therapies was not highly ranked by Veterans. This difference in preference might be explained by the stigma some attach to psychological approaches to pain treatment despite relatively strong evidence of their effectiveness. To better align patient and provider treatment preferences, especially related to psychological/behavioral interventions, a shared-decision model approach to treatment might improve overall acceptance. This approach aims to bring patients and providers together on explicit and mutually understood goals and expectations of treatment. Provider training in shareddecision principles has led to improved outcomes including provider satisfaction and improved quality of physician-patient interaction. ${ }^{23,24}$

Lastly, the difference between Veterans and VA providers concerning preferences for using marijuana for pain was especially distinct. About one-third of Veterans ranked marijuana use as one of their top three choices, whereas almost none of the providers ranked marijuana in the top three, and nearly $90 \%$ of providers placed such therapies in the lowest three rankings. Indeed, few data, other than anecdotal reports, are available supporting the use of 
marijuana for cLBP, and concerns within the medical community over toxicity and abuse remain high. ${ }^{25,26}$ On the other hand, currently, most states in the US have medical marijuana laws, and many states now permit recreational use. Formal study of the utility of marijuana for pain might help to address this disparity of opinions and foster more constructive conversations between patients and their medical providers.

Finally, to assess the interest of both Veterans with cLBP and their providers in a treatment study, a brief description of a comparative cLBP effectiveness study was provided. The average level of enthusiasm of patients for the study was high (7.1/10). Likewise, two-thirds of VA providers indicated that they would refer patients for the same study. To better understand possible barriers to study participation or Veteran referral to the study, a subset of Veterans and providers were interviewed. Interview responses were significant for varied treatment experiences and individual needs among Veterans. The opinions of participants were disparate on perceived effectiveness of low back pain treatments and what should be included in a clinical trial of low back pain, yet the willingness and enthusiasm to participate in such a clinical trial was unanimous.

Despite the many insights provided by our study, several limitations apply. First, the response rate for Veterans was low, a common limitation of many mail-based surveys. Thus, it is not clear if our conclusions apply to the general Veteran population. This concern applies even more strongly to the provider survey results. We asked about common treatment options but did not include others that might have been of interest such as acupuncture, tai chi or TENS. These or other non-surveyed options might have generated responses providing additional insight into cLBP treatment preferences. Lastly, our description of the cLBP treatment study used to gauge Veteran and provider enthusiasm was a broad overview given the range of options investigators might include in such an effort. Therefore, a specific trial design might generate greater or lesser interest depending on what treatment options are included and the eligibility criteria that are used. Factors such as participant incentives and requirements to forego currently used therapies have been noted to impact patient willingness to participate in chronic pain treatment research studies. ${ }^{27}$ The results from our survey clearly show that many Veterans with cLBP suffer from relatively severe symptoms and are receptive, as are their providers, to participating in therapeutic trials. Furthermore, these results informed the study design of our future clinical trial called the Sequential and Comparative Evaluation of Pain
Treatment Effectiveness Response (SCEPTER) Trial. SCEPTER will involve sequential treatments in two steps moving from evidenced-based treatments (pain selfmanagement, physical therapy, cognitive behavioral therapy) that were most preferred to those guideline-recommended but less well-studied second step options (yoga and spinal manipulation therapy).

\section{Acknowledgments}

We are grateful to Rachel Gruber, MSIO, CCRP for her editorial assistance with this manuscript.

\section{Funding}

VA Cooperative Studies Program.

\section{Disclosure}

David Clark reports grants from Veterans Affairs, during the conduct of the study. The authors report no other potential conflicts of interest in this work.

\section{References}

1. Institute of Medicine (US). Committee on Advancing Pain Research, Care, and Education Relieving Pain in America: A Blueprint for Transforming Prevention, Care, Education, and Research. Washington (DC): National Academies Press (US); 2011.

2. Katz JN. Lumbar disc disorders and low-back pain: socioeconomic factors and consequences. J Bone Joint Surg. 2006;88(Suppl 2):21-24. doi:10.2106/JBJS.E. 01273

3. Sox HC, Greenfield S. Comparative effectiveness research: a report from the institute of medicine. Ann Intern Med. 2009;151(3):203-205. doi:10.7326/0003-4819-151-3-200908040-00125

4. GBD. 2017 Disease and injury incidence and prevalence collaborators. Global, regional, and national incidence, prevalence, and years lived with disability for 354 diseases and injuries for 195 countries and territories, 1990-2017: a systematic analysis for the global burden of disease study 2017. Lancet. 2018;392(10159):1789-1858. doi:10.1016/S0140-6736(18)32279-7

5. Clark JD. Chronic pain prevalence and analgesic prescribing in a general medical population. J Pain Symptom Manage. 2002;23 (2):131-137. doi:10.1016/S0885-3924(01)00396-7

6. Kerns RD, Otis J, Rosenberg R, Reid MC. Veterans' reports of pain and associations with ratings of health, health-risk behaviors, affective distress, and use of the healthcare system. $J$ Rehabil Res Dev. 2003;40 (5):371-379. doi:10.1682/JRRD.2003.09.0371

7. Yu W, Ravelo A, Wagner TH, et al. Prevalence and costs of chronic conditions in the VA health care system. Med Care Res Rev. 2003;60 (3Suppl):146S-167S. doi:10.1177/1077558703257000

8. National Academies Press. National academies of sciences engineering medicine. In: Phillips JK, Ford MA, Bonnie RJ, editors. Pain Management and the Opioid Epidemic: Balancing Societal and Individual Benefits and Risks of Prescription Opioid Use. Washington (DC): National Academies Press (US); 2017.

9. Hadlandsmyth K, Mosher H, Vander Weg MW, Lund BC. Decline in prescription opioids attributable to decreases in long-term use: a retrospective study in the veterans health administration 2010-2016. J Gen Intern Med. 2018;33(6):818-824. doi:10.1007/ s11606-017-4283-8 
10. Krebs EE, Lorenz KA, Bair MJ, et al. Development and initial validation of the PEG, a three-item scale assessing pain intensity and interference. $J$ Gen Intern Med. 2009;24(6):733-738. doi:10.1007/s11606-009-0981-1

11. Cleeland CS, Ryan KM. Pain assessment: global use of the brief pain inventory. Ann Acad Med Singapore. 1994;23(2):129-138.

12. Meucci RD, Fassa AG, Faria NM. Prevalence of chronic low back pain: systematic review. Rev Saude Publica. 2015;49. doi:10.1590/ S0034-8910.2015049005874

13. Nicholas MK, Costa DSJ, Blanchard M, et al. Normative data for common pain measures in chronic pain clinic populations: closing a gap for clinicians and researchers. Pain. 2019;160(5):1156-1165. doi:10.1097/j.pain.0000000000001496

14. Von Korff M, Scher AI, Helmick C, et al. United States national pain strategy for population research: concepts, definitions, and pilot data. J Pain. 2016;17(10):1068-1080. doi:10.1016/j.jpain.2016.06.009

15. McLain RF, Kapural L, Mekhail NA. Epidural steroid therapy for back and leg pain: mechanisms of action and efficacy. Spine J. 2005;5 (2):191-201. doi:10.1016/j.spinee.2004.10.046

16. Veizi E, Hayek S. Interventional therapies for chronic low back pain. Neuromodulation. 2014;17(Suppl 2):31-45. doi:10.1111/ner.12250

17. Dima A, Lewith GT, Little P, Moss-Morris R, Foster NE, Bishop FL. Identifying patients' beliefs about treatments for chronic low back pain in primary care: a focus group study. Br J Gen Pract. 2013;63 (612):e490-498. doi:10.3399/bjgp13X669211

18. Chou R, Deyo R, Friedly J, et al. Nonpharmacologic therapies for low back pain: a systematic review for an American college of physicians clinical practice guideline. Ann Intern Med. 2017;166 (7):493-505. doi:10.7326/M16-2459

19. Foster NE, Anema JR, Cherkin D, et al. Prevention and treatment of low back pain: evidence, challenges, and promising directions. Lancet. 2018;391(10137):2368-2383. doi:10.1016/S0140-6736(18) 30489-6
20. Qaseem A, Wilt TJ, McLean RM, Forciea MA. Clinical guidelines committee of the American college of p. noninvasive treatments for acute, subacute, and chronic low back pain: a clinical practice guideline from the American college of physicians. Ann Intern Med. 2017;166(7):514-530. doi:10.7326/M16-2367

21. Kaiser RS, Mooreville M, Kannan K. Psychological interventions for the management of chronic pain: a review of current evidence. Curr Pain Headache Rep. 2015;19(9):43. doi:10.1007/s11916-015-0517-9

22. Morley S, Williams A. New developments in the psychological management of chronic pain. Can J Psychiatry. 2015;60 (4):168-175. doi:10.1177/070674371506000403

23. Sullivan MD, Leigh J, Gaster B. Training internists in shared decision making about chronic opioid treatment for noncancer pain. $J$ Gen Intern Med. 2006;21(4):360-362. doi:10.1111/j.15251497.2006.00352.x

24. Bieber C, Müller KG, Blumenstiel K, et al. Long-term effects of a shared decision-making intervention on physician-patient interaction and outcome in fibromyalgia. A qualitative and quantitative 1 year follow-up of a randomized controlled trial. Patient Educ Couns. 2006;63(3):357-366. doi:10.1016/j.pec.2006.05.003

25. Cooke AC, Knight KR, Miaskowski C. Patients' and clinicians' perspectives of co-use of cannabis and opioids for chronic noncancer pain management in primary care. Int $J$ Drug Policy. 2019;63:23-28. doi:10.1016/j.drugpo.2018.09.002

26. Jacobs NI, Montebello M, Monds LA, Lintzeris N. Survey of Australian psychiatrists' and psychiatry trainees' knowledge about and attitudes towards medicinal cannabinoids. Australas Psychiatry. 2019;27(1):80-85. doi:10.1177/1039856218803675

27. Smith SM, Gewandter JS, Kitt RA, et al. Participant preferences for pharmacologic chronic pain treatment trial characteristics: an ACTTION adaptive choice-based conjoint study. J Pain. 2016;17 (11):1198-1206. doi:10.1016/j.jpain.2016.07.008
Journal of Pain Research

\section{Publish your work in this journal}

The Journal of Pain Research is an international, peer reviewed, open access, online journal that welcomes laboratory and clinical findings in the fields of pain research and the prevention and management of pain. Original research, reviews, symposium reports, hypothesis formation and commentaries are all considered for publication. The manuscript

Submit your manuscript here: https://www.dovepress.com/journal-of-pain-research-journa management system is completely online and includes a very quick and fair peer-review system, which is all easy to use. Visit http:// www.dovepress.com/testimonials.php to read real quotes from published authors. 